\title{
PROFESORES DISTINGUIDOS DE LA UNIVERSIDAD
}

\author{
Luis Carlos Taborda R., MD*
}

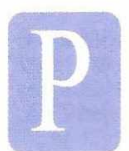

ara hablar de profesores que van haciendo su tránsito hacia ser maestros, que es en último término lo que en la ceremonia de hoy testimoniamos, qué mejor que las palabras de uno de los más grandes maestros que ha tenido la universidad colombiana. Tomo entonces en principio las expresiones de mi inolvidable amigo, el padre Alfonso Borrero ** "Hay profesores y hay maestros, muchos conocimos de los primeros, diáfanos, de explicaciones limpias, puntuales, hacendosos, comprensivos, exigentes, justos. De entre ellos uno, algunos quizás, descollaron en jerarquía espiritual indefinible. Nos dieron a más de su saber, la plenitud de su ser. Su recuerdo siembra huellas imborrables. De los profesores conservamos en listada memoria. El maestro ganó para sí persistente presencia en nuestra vida, porque desborda los límites de cortos trechos de pedagogía didáctica". La docencia no es un empleo sino una vocación. Esta vocación debe ser identificada, estimulada y cultivada muy temprano por las instituciones, que entre sus políticas tengan como una de sus prioridades la formación del talento humano, el cual constituye el patrimonio real e insustituible de cualquier proyecto educativo.

Por su parte, no basta la sola vocación como caso aislado, sino quien la tiene debe formar parte de una comunidad de atención: conocimiento, con la debida proyección para el cubrimiento de las necesidades sociales. En correspondencia con lo que aquí estamos señalando, nuestra Fundación Universitaria desea expresar públicamente su propósito de desarrollar políticas y estrategias para lograr formar y estimular el desarrollo de las vocaciones y las comunidades docente-investigativas, con proyectos como los siguientes:

1. Socializar y actualizar debidamente el estatuto docente, como un soporte de lo que aquí estamos presentando.

2. Establecer mecanismos permanentes válidos, confiables y participativos de autoevaluación de la calidad para el mejoramiento continuo.

\footnotetext{
* Vicerrector Académico, Fundación Universitaria de Ciencias de la Salud. Bogotá D.C. Colombia.

** Borrero Alfonso, S.J."El maestro", en Orientaciones Universitarias, No. 9 Pontificia Universidad Javeriana. Bogotá D.C. 1993.
}

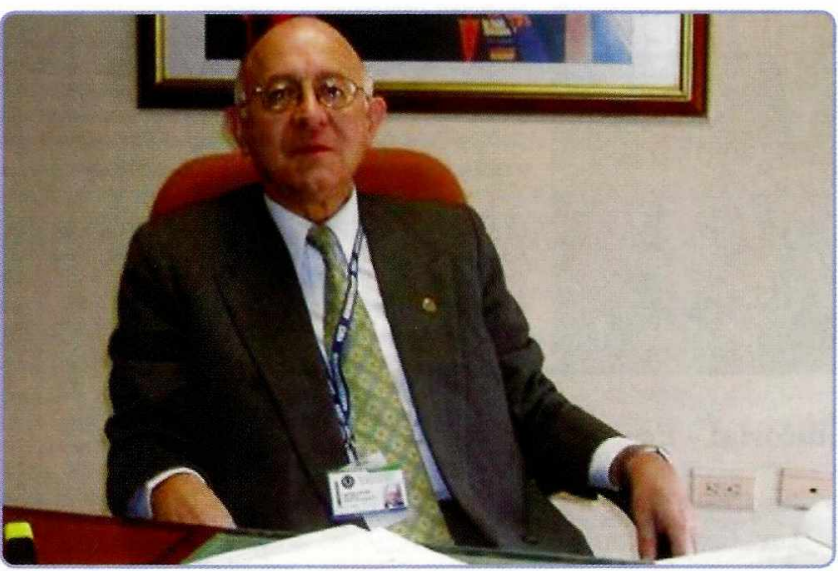

3. Poner en marcha las políticas y mecanismos necesarios y oportunos para garantizar todos los estímulos previstos en el estatuto docente, tales como:

- Procesos permanentes de capacitación.

- Ofrecimiento de becas y auxilios económicos para el logro de estos objetivos.

- Salarios adecuados en correspondencia con sus logros académicos e investigativos.

4. Hacer de manera pública el reconocimiento a la calidad de los docentes, como es el sentido de la presente ceremonia.

En efecto hoy exaltamos a cuatro queridos y ejemplares docentes, que son los profesores de:

Citohistotecnología: Myriam Puerto de Amaya.

Enfermería: Gloria Paulina Pulido Acuña.

Instrumentación Quirúrgica: Mallerly Carolina Garzón Martínez.

Medicina: Roberto Antonio Suárez Ariza.

Ellos han sido y son modelos de vocación, vida y consagración, no sólo con nuestros alumnos, nuestras instituciones, sus familias, sino para el mayor beneficio de nuestra sociedad. Me permito solicitar el más sentido aplauso para nuestros homenajeados. 